\title{
Preparation of High Purity Manganese Sulphate from Low-Grade Rhodochrosite
}

\author{
Zefang ChenLi, Laijun Ma, Lei Mao and Fang Lian* \\ School of Materials Science and Engineering, University of Science and Technology Beijing, Beijing, China
}

\begin{abstract}
In our work, the preparation technique of high pure manganese sulfate directly from low-grade rhodochrosite ore $\left(\mathrm{MnCO}_{3}\right)$ was studied and improved intensively, including the effective leaching process and the short purifying process. Based on the same ion effect, the repeated leaching of rhodochrosite with sulfuric acid is proposed to improve the solubility of $\mathrm{Mn}^{2+}$ and inhibit the dissolution of the impurities $\mathrm{Ca}^{2+}$ and $\mathrm{Mg}^{2+}$. Moreover, the repeated leaching process could make full use of rhodochrosite and lower the dosage of sulfuric acidas raw material. With the aid of theoretical calculation, $\mathrm{Ba}(\mathrm{OH})_{2}$ was chose to adjust the $\mathrm{pH}$ value of manganese sulfate solution, and $\mathrm{BaF}_{2}$ to remove $\mathrm{Ca}^{2+}$ and $\mathrm{Mg}^{2+}$ completely in the process of purifying. The results demonstrate that the extraction ratio and the recovery ratio of manganese reached $94.3 \%$ and $92.7 \%$, respectively, which shows the prospect of industrial application. In manganese sulfate production, the heavy metal impurities have been decreased to less than 1ppm. Moreover, the content of calcium, magnesium and sodium has been decreased to less than 20ppm, which meets the standards of high pure reagent for energy and electronic materials. Our study enlightens an approach to the sustainable application of low-grade rhodochrosite.
\end{abstract}

Keywords: low-grade rhodochrosite; effective leaching; short purifying process; recovery ratio; high purity

\section{Introduction}

Low-grade manganese carbonate ores $(\leq 14 \%)$ becomes gradually the main resources for exploitation and applications in China according to national mineral resources survey (Tan et al 2004 and Singh et al 2017). Therefore, the electrolytic deposition technique of rhodochrosite faces great challenges including low electrolysis efficiency, high-resource input and highpollution discharge (Fu et al 2010, Michelis et al 2009, Zhang et al 2013). Recently, more and more amount of manganese series with high or super high purity such as $\mathrm{MnSO}_{4}, \mathrm{MnO}_{2}, \mathrm{Mn}_{3} \mathrm{O}_{4}$ and $\mathrm{MnO}$ is demanded with the development of energy and electronic materials. Due to lowgrade ores containing multiple elements such as iron, silicon, calcium and magnesium, conventional preparation of manganese sulphate with high purity from electrolytic product is characterized by long production-cycle and highenergy consumption (Subrat et al 2011, Mpho et al 2013). By contrast, hydrometallurgical method combined with thermal decomposition, hydrothermal synthesis and sol-gel processes has been widely studied because of its high efficiency, low consumption and low cost (Chen et al 2008). But the key problem in direct preparation of manganese series form low-grade rhodochrosite is to remove completely the multiple impurities such as iron, silicon, calcium and magnesium (Liu et al 2014). So it is urgent to develop a sustainable alternative approach with character of short process, high efficiency and environmental friendly.

In our work, the preparation technique of manganese sulphate with high purity directly from low-grade rhodochrosite ore (Mn grade of concentration is 13.86\%) was studied and improved intensively. In detail, the leaching process was optimized firstly using orthogonal experiment, where the effects of solid-liquid ratio, temperature and duration on the leaching rate of manganese were discussed under certain conditions of mineral-to-acid ratio (1:0.7) and stirring speed $(300 \mathrm{r} / \mathrm{min})$. More importantly, the repeated leaching of rhodochrosite with sulfuric acid is proposed herein to improve the solubility of $\mathrm{Mn}^{2+}$ and inhibit the dissolution of the impurities $\mathrm{Ca}^{2+}$ and $\mathrm{Mg}^{2+}$, simultaneously. Additionally, the short purifying process is also explored with the aid of theoretical calculation. The recovery ratio of manganese and removal ratio of the impurity were evaluated via chemical titration and ICP analysis, respectively. Furthermore, comparison between conventional preparation technique from electrolytic manganese and a sustainable approach directly from low-grade rhodochrosite have also been done herein.

\section{Experimental}

The rhodochrosite samples were provided by BaoJing Tianhe Manganese Industry Company, Hunan province, China. And the samples were ground to powder with $\leq 2 \mathrm{~mm}$ in diameter.

Firstly, the leaching process was optimized using orthogonal experiment. $10 \mathrm{~g}$ rhodochrosite powder, $3.6 \mathrm{ml}$ sulfuric acid solution (98\%) and deionized water were added into a $150 \mathrm{ml}$ conical flask with solid-liquid ratio of $1: 5-1: 7$ in weight and mixed for $1-3 \mathrm{~h}$ at $75-95^{\circ} \mathrm{C}$ under vigorous stirring $(300 \mathrm{r} / \mathrm{min})$. Then the residues in the flask were filtered, washed and dried. Finally, the optimal

* Corresponding Author: F. Lian, lianfang@ mater.ustb.edu.cn, phone: +86 10-82377985

Copyright @ 2017 Canamaple Academia Services, http://press.camdemia.ca

DOI: $10.15273 /$ gree.2017.02.042 
parameters were determined by employing the leaching rate of manganese as the primary standard.

Then based on the optimal process parameters, the repeated leaching approach for rhodochrosite is performed herein. In detail, $10 \mathrm{~g}$ rhodochrosite powder, Xml sulfuric acid solution $(98 \%)$ and deionized water were added into the initial leaching solution with solid-liquid ratio of $1: 7$ in weight and stirred for $2 \mathrm{~h}$ at $85^{\circ} \mathrm{C}$ (stirring speed $300 \mathrm{r} / \mathrm{min}$ ). Then the residues were filtered to get the first repeated leaching solution. And the aforementioned procedures were repeated 0-4 times, so the total leaching times disperse in the range of 1-5. Moreover, the amount of sulfuric acid solution for each addition was calculated as the following formula:

$$
\mathrm{X}=0.0779 \mathrm{a}-\mathrm{ab} / 38.25
$$

where $\mathrm{X}$ is the volume of sulfuric acid solution ( $\mathrm{ml})$, $\mathrm{a}$ is the total volume of the leaching solution $(\mathrm{ml})$ and $\mathrm{b}$ is the concentration of $\mathrm{H}^{+}$in the leaching solution ( $\left.\mathrm{mol} / \mathrm{l}\right)$.

In the purification process, the coarse manganese sulphate solution was adjusted to $\mathrm{pH}=4.0$ using $\mathrm{Ba}(\mathrm{OH})_{2}$ solution. After standing for $24 \mathrm{~h}$, the precipitate was filtered. Subsequently, $\mathrm{BaF}_{2}$ powder was introduced in the solution and stirred at $25^{\circ} \mathrm{C}$ for $3 \mathrm{~h}$. Then the precipitate was separated and the filtrate was adjusted to $\mathrm{pH}=8.0$ using $\mathrm{Ba}(\mathrm{OH})_{2}$ solution. Finally, the precipitate was filtered repeatedly and pure $\mathrm{MnSO}_{4}$ solution was expected to be obtained.
The mineral and chemical composition of the rhodochrosite samples was chemically analyzed via XRD and chemical titration, respectively. The recovery ratio of manganese was evaluated via chemical titration with ammonium ferrous sulfate. The concentration of impurities such as calcium and magnesium ions was determined by ICP analysis.

\section{Results and Discussion 3.1 The composition of rhodochrosite samples}

The chemical composition of rhodochrosite samples is listed in Table 1. And the concentration of manganese is only $13.86 \%$, which is typical low-grade manganese carbonate ores. In addition, the rhodochrosite samples are mainly composed ofMnCO $3, \mathrm{SiO}_{2}, \mathrm{CaMg}\left(\mathrm{CO}_{3}\right)_{2}, \mathrm{FeSO}_{3}$ and $\mathrm{Al}_{2} \mathrm{O}_{3}$ as shown in Figure 1.

\subsection{The initial optimization of leaching process}

The experiments for orthogonal analysis on leaching were performed, and the detail parameters are shown in Table 2. The maximum of the extraction ratio of $\mathrm{Mn}$ reaches $98.41 \%$. Moreover, $\mathrm{R}$ is calculated to represent the influence of each factor on the leaching efficiency. The results demonstrate that the liquid:solid ratio has the greatest effect on the leaching efficiency, followed by temperature and duration.

Table 1. The major chemical composition of the rhodochrosite samples ( $\%$ by weight).

\begin{tabular}{ccccccccc}
\hline $\mathbf{M n}$ & $\mathbf{C a}$ & $\mathbf{K}$ & $\mathbf{M g}$ & $\mathbf{N i}$ & $\mathbf{Z n}$ & $\mathbf{N a}$ & $\mathbf{F e}$ & $\mathbf{S i}$ \\
\hline 13.86 & 3.80 & 1.80 & 1.32 & $<0.005$ & 0.023 & 0.86 & 3.10 & 16.63 \\
\hline
\end{tabular}

Table 2. The leaching process parameter for the orthogonal experiments.

\begin{tabular}{ccccc}
\hline Number & Liquid-to-solid ratio & $\begin{array}{c}\text { Temperature } \\
\text { / } \mathbf{C}\end{array}$ & $\begin{array}{c}\text { Duration } \\
\text { /h }\end{array}$ & $\begin{array}{c}\text { Leaching efficiency } \\
\text { /\% }\end{array}$ \\
\hline S1 & $5: 1$ & 75 & 1 & 80.25 \\
S2 & $5: 1$ & 85 & 2 & 90.48 \\
S3 & $5: 1$ & 95 & 3 & 88.89 \\
S4 & $6: 1$ & 75 & 2 & 88.89 \\
S5 & $6: 1$ & 85 & 3 & 90.48 \\
S6 & $6: 1$ & 95 & 1 & 87.30 \\
S7 & $7: 1$ & 75 & 3 & 95.24 \\
S8 & $7: 1$ & 85 & 1 & 95.24 \\
S9 & $7: 1$ & 95 & 2 & 98.41 \\
Mean value 1 & 86.540 & 88.127 & 87.597 & - \\
Mean value 2 & 88.890 & 92.067 & 92.593 & - \\
Mean value 3 & 96.297 & 91.533 & 91.007 & - \\
Range & 9.757 & 3.940 & 4.996 & \\
\hline
\end{tabular}


Table 3. Variance analysis of orthogonal experiment.

\begin{tabular}{ccccc}
\hline Variance originates & Sum of squares & Freedom degree & Fratio & F crit \\
\hline liquid-solid ratio & 155.574 & 2 & 2.078 & 5.140 \\
temperature & 27.413 & 2 & 0.366 & 5.140 \\
Duration & 41.607 & 2 & 0.556 & 5.140 \\
\hline
\end{tabular}

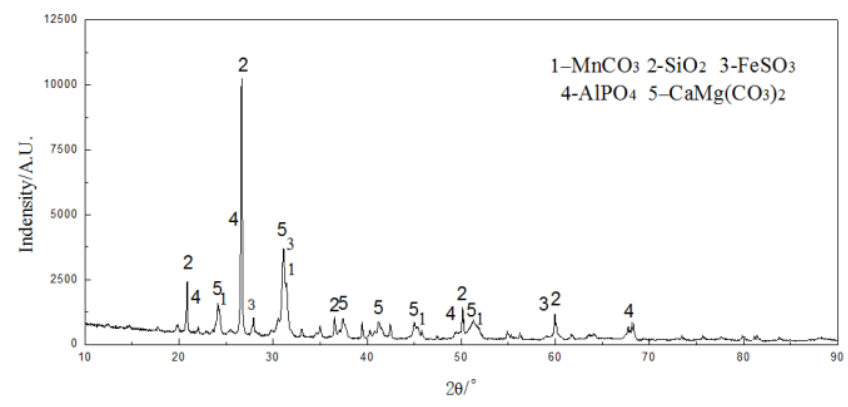

Figure 1. XRD results of the manganese ore.

Furthermore, the variance analysis is shown in Table 3. Fratio value is far less than the critical one, indicating that the experimental error is within the allowable range. It is important to note that Fratio value of liquid:solid ratio was obviously higher than that of the other two factors, demonstrating the greatest effect of liquid:solid ratio among the considered three main factors and consistency with the range analysis. The optimal parameters including leaching temperature at $85^{\circ} \mathrm{C}$, liquid-to-solid ratio of $7: 1$ and leaching duration of $2 \mathrm{~h}$ are determined and adopted in the further studies.

\subsection{The repeated leaching process}

In the repeated leaching process, the accumulative content of impurity in the leaching solution and the extraction ratio of Mn were characterized by ICP. The standard deviation for the four parallel experiment results is below $0.73 \%$, and the average concentration values are given in Table 4.

Table 4. The average value of ICP analysis of ionic concentration in the repeated leaching solution.

\begin{tabular}{lccccc}
\hline $\begin{array}{l}\text { Total leaching } \\
\text { times }\end{array}$ & $\mathbf{1}$ & $\mathbf{2}$ & $\mathbf{3}$ & $\mathbf{4}$ & $\mathbf{5}$ \\
\hline $\mathrm{Mn}^{2+}(\mathrm{g} / \mathrm{L})$ & 19.42 & 38.49 & 56.02 & 71.44 & 84.05 \\
$\mathrm{Ca}^{2+}(\mathrm{mg} / \mathrm{L})$ & 540.2 & 533.7 & 522.2 & 504.0 & 486.0 \\
$\mathrm{Mg}^{2+}(\mathrm{mg} / \mathrm{L})$ & 1027.3 & 1165.0 & 1277.6 & 1425.0 & 1687.2 \\
\hline
\end{tabular}

Figure 2 demonstrates that the concentration of manganese is enhanced significantly and the accumulative content of $\mathrm{Ca}^{2+}$ is reduced obviously with the increase of the repeated leaching times. Though the absolute concentration of $\mathrm{Mg}^{2+}$ increases, its extraction ratio is reduced in the repeated leaching process. Based on the same ion effect, the repeated leaching approach not only improves the solubility of $\mathrm{Mn}^{2+}$ but also inhibits the dissolution of the impurities $\mathrm{Ca}^{2+}$ and $\mathrm{Mg}^{2+}$.

\subsection{The purifying process}

The main impurities in the coarse manganese sulphate solution obtained from the leaching process consist of $\mathrm{Al}^{3+}$, $\mathrm{Fe}^{2+}, \mathrm{Fe}^{3+}, \mathrm{Mg}^{2+}, \mathrm{Ca}^{2+}$ and a small quantity of heavy metals. Among them, a large proportion of $\mathrm{Ca}^{2+}$ ions could be precipitated with $\mathrm{SO}_{4}{ }^{2-}$ and removed with insoluble silica. Moreover, iron and aluminum ions are both participate in hydrolysis at $\mathrm{pH}=3.0-8.0$ and separated from the filtrate. Both $\mathrm{Ca}^{2+}$ and $\mathrm{Mg}^{2+}$ were removed by adding $\mathrm{BaF}_{2}$ as the precipitant at $\mathrm{pH}=4.0$. Finally, the heavy metals can be removed via adjusting $\mathrm{pH}=8.0$ with $\mathrm{Ba}(\mathrm{OH})_{2}$.
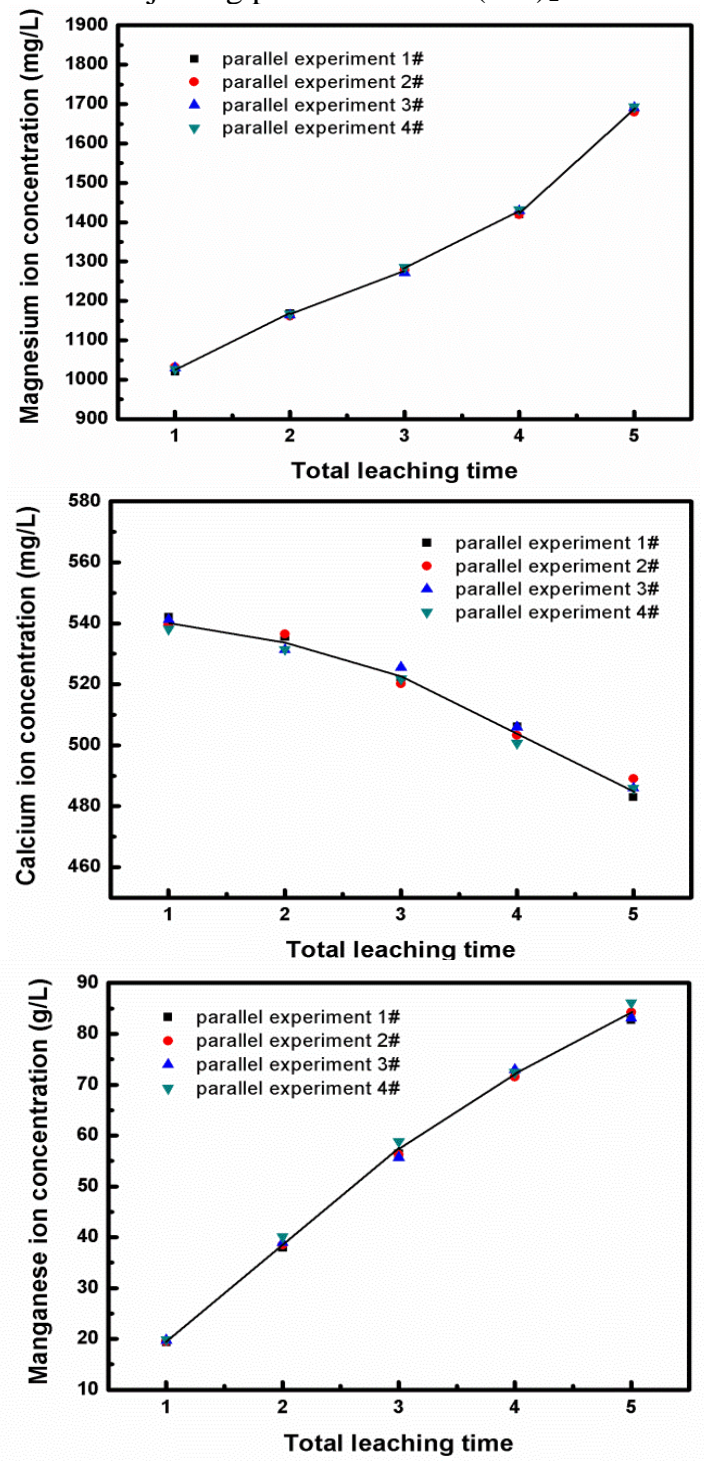

Figure 2. Effect of the leaching times on the ionic concentration. 
Table 5. ICP analysis of the manganese sulfate solution.

\begin{tabular}{cccccc}
\hline $\mathbf{C a}$ & $\mathbf{M g}$ & $\mathbf{N i}$ & $\mathbf{F e}$ & $\mathbf{A l}$ & $\mathbf{N a}$ \\
$/ \mathbf{p p m}$ & $/ \mathbf{p p m}$ & $/ \mathbf{p p m}$ & $/ \mathbf{p p m}$ & $/ \mathbf{p p m}$ & $/ \mathbf{p p m}$ \\
\hline 2.599 & 15.82 & 0.187 & 0.083 & 0.006 & 15.82 \\
\hline
\end{tabular}

According to ICP analysis of the manganese sulfate solution in Table 5, the heavy metal impurities such as Fe and $\mathrm{Ni}$ have been decreased to less than 1ppm, and the content of calcium, magnesium, sodium has been decreased to less than 20ppm, which meet standards of high pure reagent for energy and electronic materials. Mn content in the manganese sulfate solution is determined by titration with ammonium ferrous sulfate. The recovery ratio of manganese reaches $92.7 \%$.

In compare with conventional technique from electrolytic manganese, the power consumption has been reduced to $\leq 2000 \mathrm{kWh} / \mathrm{t}$ (product) in our short-process approach. Moreover, comprehensive recovery rate of manganese increases significantly. As know, the quality of wastewater which occurred in the process of electrolytic deposition is complex, containing toxic substances and high content of ammonia/nitrogen. By contrast, the wastewater generated from our short-process approach shows low content of ammonia/nitrogen about $500 \mathrm{mg} / \mathrm{t}$ (product) and no toxic emissions. Our study contributes to the sustainable application of low-grade manganese ore.

\section{Conclusions}

A hydrometallurgical process including the effective leaching process and the short purifying process from lowgrade rhodochrosite ore $(13.86 \%)$ has been developed in the paper. The results demonstrate that the extraction ratio and the recovery ratio of manganese reach $94.3 \%$ and $92.7 \%$, respectively.

According to the orthogonal experimental results, the optimal parameters of the leaching process are determined: mineral-to-acid ratio of $1: 0.7$, leaching temperature at $85^{\circ} \mathrm{C}$, liquid-to-solid ratio at $7: 1$, and duration of $2 \mathrm{~h}$. The extraction ratio of $\mathrm{Mn}$ reaches more than $98 \%$. Moreover, the concentration of manganese is accumulated in the repeated leaching solution, and simultaneously the extraction ratio of impurities of $\mathrm{Ca}^{2+}$ and $\mathrm{Mg}^{2+}$ is reduced significantly. The repeated leaching method provides an approach to the effective use of the low-grade rhodochrosite and the reduction of the wastewater discharge. In addition, $\mathrm{BaF}_{2}$ is chose as precipitant to remove $\mathrm{Ca}^{2+}$ and $\mathrm{Mg}^{2+}$ completely. The process of purifying is combined with adjustment of the $\mathrm{pH}$ value of manganese sulfate solution using $\mathrm{Ba}(\mathrm{OH})_{2}$, which contributes to a high removal rate of impurities and a short application process.

\section{Acknowledgement}

This work was financially supported by the National Science and Technology Pillar Program (2015BAB01B02).

\section{References}

Chen, N.X. and Z.W. Liao, 2008. Effect of electrolyte composition on the production of electrolytic manganese metal. Manganese Industry in China, 26(4): $5-8$.

Fu, J.G., Z.X. He, H. Wang, W. Liang and C. Guo, 2010. Preparation of chemical manganese dioxide from manganese sulfate. Mining Science and Technology, 20(6): 877 - 881.

Michelis, I.D., F.Ferella, F. Beolchini, A. Olivieri and F. Vegliò, 2009. Characterisation and classification of solid wastes coming from reductive acid leaching of low-grade manganiferous ore. Journal of Hazardous Materials, 162(2-3):1285 - 1291

Mpho, M., B. Samson and A. Ayo, 2013. Evaluation of reduction roasting and magnetic separation for upgrading $\mathrm{Mn} / \mathrm{Fe}$ ratio of fine ferromanganese. International Journal of Mining Science and Technology, 23(4): 537 - 541.

Subrat, M., M.B. Kumar, D. Nilima and R.D. Srinivas, 2011. Ore petrography of low-grade siliceous manganese ores from the Bonai-Keonjhar belt, Orissa, India: the influence of mineral-fabric on their beneficiation. Mining Science and Technology, 21(6): $803-808$.

Tan, Z.Z., G.G. Mei and W.J. Li, 2004. Manganese metallurgy. Changsha, Central South University Press.

Singh, V. and A. Biswas, 2017. Physicochemical processing of low grade ferruginous manganese ores. International Journal of Mineral Processing, 158: 35 44.

Liu, Y.C., Q.Q. Lin and L.F. Li, 2014. Study on hydrometallurgical process and kinetics of manganese extraction from low-grade manganese carbonate ores. International Journal of Mining Science and Technology, 24(4): 567 - 571.

Zhang, Y.B., Z.X. You, G.H. Li and T. Jiang, 2013. Manganese extraction by sulfur-based reduction roasting-acid leaching from low-grade manganese oxide ores. Hydrometallurgy, 133(1): 126 - 32. 